\title{
Iniencephaly with Long Survival: A Rare Condition
}

\author{
Souad Bakhti ${ }^{{ }^{*}}$, Nabila Tighilt ${ }^{2}$, Wahiba Khoudir ${ }^{3}$, Mohamed Djennas ${ }^{4}$ \\ ${ }^{1}$ Professor, Pediatric Neurosurgery Division, Mustapha Pacha University Hospital, Algiers, Algeria \\ ${ }^{2}$ Assistant Professor, Pediatric Neurosurgery Division, Mustapha Pacha University Hospital, Algiers, Algeria \\ ${ }^{3}$ Consultant in Neurosurgery, Department of Neurosurgery, Mustapha Pacha University Hospital, Algiers, Algeria \\ ${ }^{4}$ Professor, Chief Department of Neurosurgery, Mustapha Pacha University Hospital, Algiers, Algeria
}

* Corresponding Author Address: Place 1er Mai, Algiers, Algeria. Tel: +213661411881. Fax: +21323860025. Email: bak-sou@hotmail.com

Article Type: Case Report

Received: June 18, 2016, Last Revised: October 15, 2016, Accepted: December 15, 2016, Published: December 30, 2016

\section{Abstract}

Background \& Importance: Iniencephaly is a rare cranio-cervical deformity. It belongs to neural tube defects. This disorder is characterized by a retroflexion of head, a very short neck, varying degrees of incomplete posterior closure of vertebrae and cervical and thoracic spinal synostosis. This malformation is associated with central nervous system and systemic malformations. Most of patients are dead born and others die after few hours of life. There are only few long-term survivors reported in literature.

Case Presentation: A seven-year-old girl with iniencephaly signs who has been managed conservatively and still alive after six years of follow-up.

Conclusion: Iniencephaly is a rare complexe disorder with a dismal prognosis but not uniformly fatal.

Keywords: Iniencephaly; Neural Tube Defect; Spine

Please cite this paper as: Bakhti S, Tighilt N, Khoudir W, Djennas M. Iniencephaly with Long Survival: A Rare Condition. IrJNS. 2016;2(3):19-21

\section{Background and Importance}

Iniencephaly is a rare disease which was described for the first time by Saint Hilaire in 1836. The description was then completed by Lewis in 1847 and Ballantyne in 1906 [1]. This complex malformation is a part of neural tube defects, and etiologic factors are probably numerous with environmental and genetic involvement $[2,3]$. This disorder is clinically characterized by a retroflexion of head, a very short neck, a marked lordosis of the cervical spine, and in many cases an upward turned face [3-5]. Anatomically, the malformation is represented by enlargement of foramen magnum, varying degrees of cervical and thoracic vertebrae fusion, and incomplete closure of posterior arches of cervical vertebrae [3-6]. Several associated malformations of central nervous system have been described [7]. Diagnosis can be made in utero by ultrasonography $[3,6]$ and lead in many cases to termination of pregnancy. Iniencephaly has uniformly a dismal prognosis, and very few cases have been reported with a long survival [6, 8-11]. We reported a girl with iniencephaly diagnosed at the age of seven years who is still alive after a follow-up of six years.

\section{Case Presentation}

A seven-year-old girl was referred to our department on February 2010 for exploration of a cranio-vertebral malformation.
At the examination, the girl was alert without mental delay and good results at school. She presented a retroflexion of head and a short neck (Figure 1). She had also a congenital palsy of the right sixth nerve. Chest was normal. Imaging revealed an hyperlordosis of the cervical spine and enlargement of foramen magnum, spina bifida occulta of the first and second cervical vertebrae (Figure 2) and fusion of the third, fourth and fifth cervical vertebrae (Figure 3). MRI showed a split of medulla and a cerebellar mass lesion extending in occipital bone which is probably a dermoid cyst (Figure 4). Other investigations precluded other systemic malformations. According to the clinical and radiological features, we have concluded to the diagnosis of mild form of iniencephaly. The patient was managed conservatively since she was not disabled in her daily life. She is still under clinical and radiological monitoring, and follow-up is of six years.

\section{Discussion}

Iniencephaly is a part of neural tube defects as anencephaly, encephaloceles and spina bifida $[2,6]$. Incidence of this disease is thought to be between $1 / 1000$ and $1 / 100,000$ births. There is a female preponderance with a sex ratio of $1: 3$ to $1: 9[3,6]$; our patient was also a female. Iniencephaly is the result of a disorder of development of the skull base and the cervico-thoracic spine before the closure of the anterior neuropore at the 24th day of gestation [6]. There is no definite evidence for etiologic factors, 


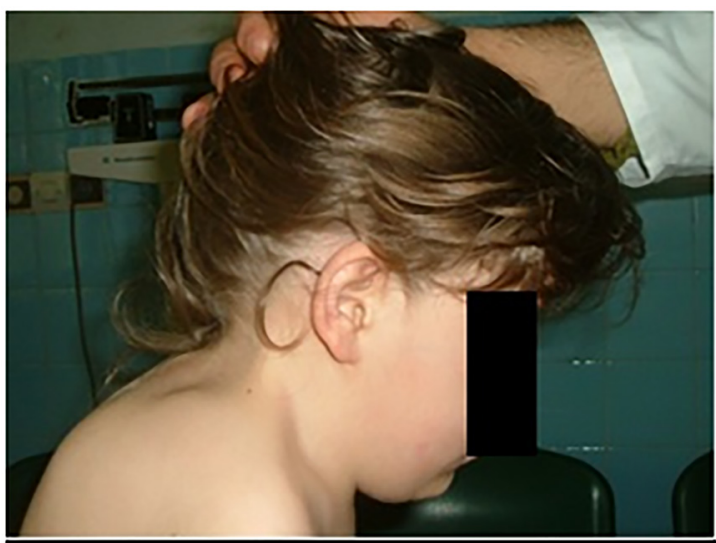

Figure 1. Short Neck in Patient under Study

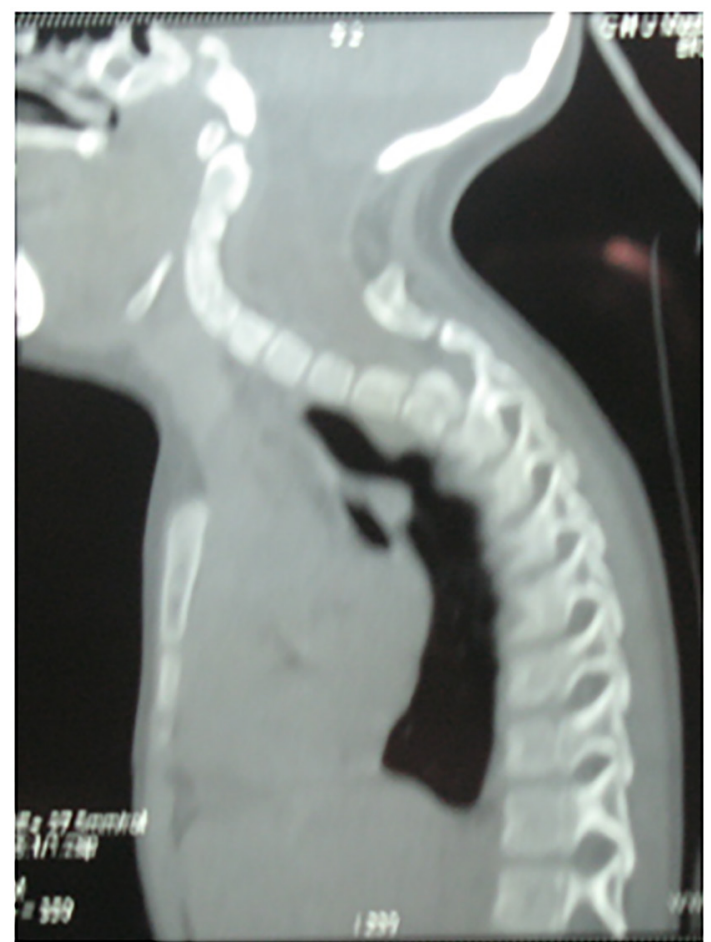

Figure 2. 2D CT Scan Reconstruction Showing Enlargement of Foramen Magnum and Absence of Posterior Arches of C1 and C2

but it seems that there are nutritional, environmental and genetic factors $[2,3]$. The malformation can be observed in families with history of neural tube defects. There was no history of neural tube defect in the present case. Iniencephaly is characterized by a variable defect of occipital bone resulting in enlargement of foramen magnum, a partial or total absence of the cervical and thoracic vertebrae with fusion in some cases, a varying degree of incomplete posterior fusion of vertebrae, important shortening of the spine consecutive to a marked lordosis and hyperextension of the spinal column [3-6]. There is generally an upward turned face with mandibular skin directly continuous with that of the chest [3]. Our patient had a short neck, an enlarged foramen magnum, spina of the first and the second cervical vertebrae and fusion of inferior cervical vertebrae. Thoracic spine was not involved. Based on these features, we have concluded that our patient had a mild form of iniencephaly. This form has been described by some authors

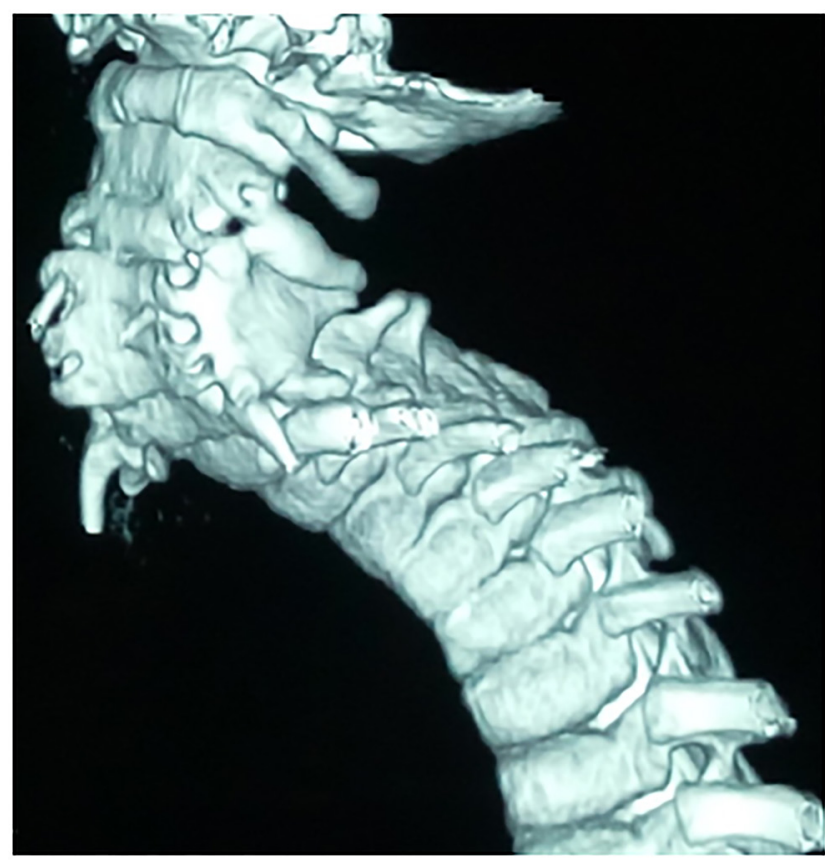

Figure 3. 3D CT Scan Reconstruction Showing Fusion of Cervical Vertebrae

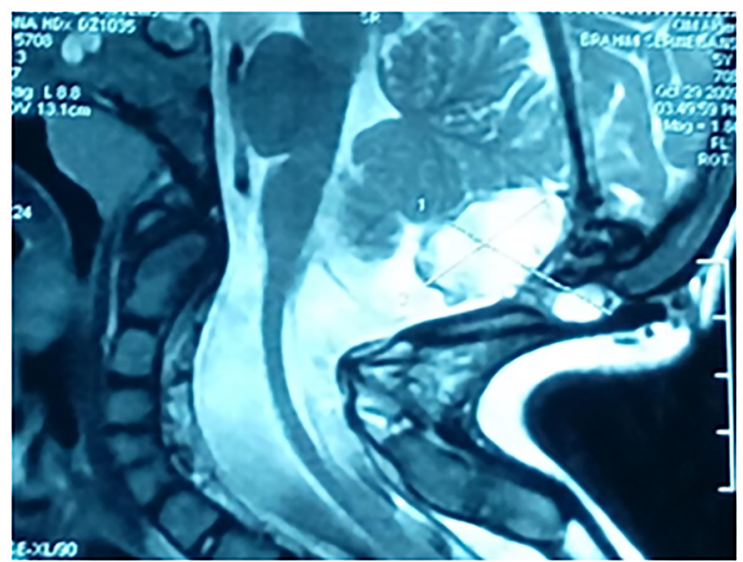

Figure 4. Sagittal View T2 MRI Showing Cerebellar Mass Lesion Extending in Occipital Bone

$[8,11]$. Lewis has classified iniencephaly in two main groups: iniencephaly apertus which is associated with cephalocele and iniencephaly clauses which is associated with spinal defect but no cephalocele [3]. Our patient was in the second category. Iniencephaly and Klippel-Feil syndrome were confused in the past. In both conditions, fibrous bands connecting occiput and cervical spine are present; this leads to retroflexion of the cervical spine. However, there is an enlarged foramen magnum communicating with the spinal canal through posterior spinal defect in iniencephaly. Difference between the aforementioned disorders can be made by 3D CT [11].

Iniencephaly can be associated with nervous and other systemic malformations. Nervous malformations such as anencephaly, posterior encephalocele, microcephaly, polymicrogyria, glial heterotopias, atresia of the ventricular system, disorganization of brain stem and or spinal cord, vermian agenesis, and cerebellar cyst are not specific and 
various $[3,7,12,13]$. Our patient had a duplication of medulla and a cerebellar lesion which is probably a demoidcyst. It is of note that nature of cerebellar cysts observed in iniencephaly is not always specified in literature. Systemic malformations are numerous such as omphalocele, diaphragmatic defect with hernia, gastrointestinal malformations, cardiovascular and genitourinary malformations, hypoplastic lungs, single nostril, facial cleft, cyclopia, club feet and arthrogriposis. There is, in some instances, an overgrowth of arms compared to legs [14]. Our patient didn't exhibit any of these malformations.

Prenatal diagnosis can be made by ultrasonography, but evaluation must be careful. Pungavkar (2007) proposed to add an ultrafast MRI when there is a suspicion of iniencephaly on ultrasonography. When prenatal diagnosis is made, termination of pregnancy is proposed in some countries [6].

Iniencephaly is almost invariably lethal. At our knowledge, there are very few papers in Anglo-Saxon literature describing patients alive $[2,8-11,15,16]$. Our patient is still alive at 13 years. Age of cases alive reported varied from two months to 24 years [9]. All the cases seem to be mild form of iniencephaly. The oldest patient has been operated in infancy for cervico-occipital meningoencephalocele and has a ventriculoperitoneal shunt; she has a normal intellect and lives independently [3]. Surgery has been proposed for some patients alive because the deformity is important and handicaps them $[10,16]$. Authors proposed suboccipital release, gradual flexion of head in halo brace and subsequent occipito-cervical fusion to maintain correction. We have decided to practice a conservative management for our patient since she had a quite normal daily life.

\section{Conclusion}

Iniencephaly is a very rare neural tube defect with numerous associated malformations. Prenatal diagnosis can be made at the first trimester of pregnancy by ultrasonography and can lead to abortion. However, mild form exists and can be compatible with long survival. The prognosis of this disorder is dismal but not uniformly fatal.

\section{Funding}

None.

\section{Conflicts of Interest}

The authors declare no conflict of interest.

\section{Author's Contribution}

Conception and Design: All authors. Data Collection: All authors. Drafting the Article: All authors. Critical Revising the Article: All authors. Reviewing Submitted Version of Manuscript: All authors. Approving the Final Version of the Manuscript: All authors.

\section{References}

1. Aleksic S, Budzilovich G, Greco M, Feigin I, Epstein F, Pearson J. Iniencephaly: a neuropathologic study. Clinical neuropathology. 1982;2(2):5561.

2. Côté M, Turmel A, Michaud K, Lavoie P, Francoeur J, Picard C. Iniencephaly in an Adult Patient. The Canadian Journal of Neurological Sciences. 2012;39(03):385-7.

3. Pungavkar SA, Sainani NI, Karnik AS, Mohanty PH, Lawande MA, Patkar DP, et al. Antenatal diagnosis of iniencephaly: sonographic and MR correlation: a case report. Korean journal of radiology. 2007;8(4):351-5.

4. Chen C-P. Prenatal diagnosis of iniencephaly. Taiwanese Journal of Obstetrics and Gynecology. 2007;46(3):199-208.

5. Erdinçler P, Kaynar MY, Canbaz B, Koçer N, Kuday C, Çiplak N. Iniencephaly: neuroradiological and surgical features: Case report and review of the literature. Journal of neurosurgery. 1998;89(2):317-20.
6. Jeanne-Pasquier C, Carles D, ALBERTI E-M, Jacob B. Iniencéphalie: à propos de 4 nouvelles observations et revue de la littérature. Journal de gynécologie obstétrique et biologie de la reproduction. 2002;31(3):276-82.

7. Doğan MM, Ekici E, Yapar EG, Soysal ME, Soysal SK, Gökmen O. Iniencephaly: sonographic-pathologic correlation of 19 cases. Journal of Perinatal MedicineOfficial Journal of the WAPM. 1996;24(5):501-11.

8. Aytar MH, Doğulu F, Cemil B, Ergün E, Kurt G, Baykaner K. Iniencephaly and long-term survival: a rare case report. Child's Nervous System. 2007;23(6):719-21. 9. Basu S, Muthusami S, Bhutada A, Kumar A. Iniencephaly: Association with unusual congenital malformations. Indian journal of pediatrics. 2008;75(11):118990.

10. Gartman JJ, Melin TE, Lawrence WT, Powers SK. Deformity correction and long-term survival in an infant with iniencephaly: Case report. Journal of neurosurgery. 1991;75(1):126-30.

11. Munden M, Macpherson R, Cure J. Iniencephaly: 3D-computed tomography imaging. Pediatric radiology. 1993;23(7):572-.

12. KC Loo BF, Dorota Stanford, Christine. CNS findings in iniencephaly: case report and literature review. Pathology. 2001;33(1):112-5.

13. Tugrul S, Uludoğan M, Pekin O, Uslu H, Çelik C, Ersan F. Iniencephaly: Prenatal diagnosis with postmortem findings. Journal of Obstetrics and Gynaecology Research. 2007;33(4):566-9.

14. collaborators C-. Effect of tranexamic acid in traumatic brain injury: a nested randomised, placebo controlled trial (CRASH-2 Intracranial Bleeding Study). BMJ. 2011;343:d3795.

15. Katz VL, Aylsworth AS, Albright SG. Iniencephaly is not uniformly fatal. Prenatal diagnosis. 1989;9(8):595-9.

16. Sherk HH, Shut L, Chung S. Iniencephalic deformity of the cervical spine with Klippel-Feil anomalies and congenital elevation of the scapula. JBJS Case Connector. 1974(6):1254-9.

\section{Comments}

This article presented a case of iniencephaly with long-term survival. This malformation is characterized by a triad of the occipital bone defect, cervical dysraphism and fixed retroflexion of the head. In the past decades, it was considered almost invariably lethal, but in recent years, there are growing numbers of long-term survival even to adulthood. It seems that inencephaly forms a spectrum, from mild form to sever form. This is very important, because in the past abortion has been suggested in the cases that prenatal sonography showed this anomaly, but it seems that some neonates with this anomaly had normal IQ and development.

In this article, the patients' brain images were not presented. Associated findings in brain, such as hydrocephaly, should be considered and managed properly, although more severe forms have anencephaly. The role of surgery in these cases should be clarified. Correction of craniocervical deformity may be considered in patients with disability or sign of cervical cord compression.

Amir Azarhomayoun, MD,

1. Sina Trauma and Surgery Research Center, Tehran University of Medical Sciences, (TUMS), Tehran, Iran

2. Gumdishapour Academy of Neuroscience (GAN), Ahvaz, Iran 